\title{
The Adipose Mesenchymal Stem Cell Secretome Inhibits Inflammatory Responses of Microglia: Evidence for an Involvement of Sphingosine-1-Phosphate Signalling
}

\author{
Giovanni Marfia,, ${ }^{1, *}$ Stefania Elena Navone, ${ }^{1, *}$ Loubna Abdel Hadi, ${ }^{2, *}$ Moira Paroni, ${ }^{3}$ Valeria Berno, \\ Matteo Beretta, ${ }^{1}$ Roberta Gualtierotti, ${ }^{4}$ Francesca Ingegnoli, ${ }^{4}$ Vincenzo Levi, ${ }^{1}$ Monica Miozzo, Jens Geginat, ${ }^{3}$ \\ Lorenzo Fassina, ${ }^{6}$ Paolo Rampini, ${ }^{1}$ Carlo Tremolada, Laura Riboni, ${ }^{2, \dagger}$ and Rolando Campanella ${ }^{1, \dagger}$
}

Central nervous system (CNS) inflammation is primarily driven by microglial cells which secrete proinflammatory cytokines and undergo proliferation upon activation, as it occurs in neurodegenerative diseases. Uncontrolled or prolonged CNS inflammation is potentially harmful and can result in cellular damage. Recently, many studies have focused on human adipose tissue as an attractive source of cytokines with immunosuppressive properties that potentially modulate inflammation. Our study aimed to evaluate if different methods of human tissue collection could affect adipose mesenchymal stem cell (ADSC)-derived cytokine secretion and investigate the effects of ADSC secretome in modulating microglia activation and the possible implication of sphingosine-1-phosphate (S1P) in these effects. Our results demonstrate that the conditioned medium (CM) of ADSCs isolated by two different processing methods (lipoaspirate and Lipogems) significantly inhibited the lipopolysaccharide (LPS)-induced effects on microglia activation, including microglial expression of CD68, cytokine secretion, proliferation, and migration. Pulse studies with radiolabeled sphingosine demonstrated that LPS treatment of resting microglia induced a significant increase of both cellular and extracellular S1P. Moreover, and of relevance, FTY720, a functional antagonist of S1P receptor, inhibited the multiple LPS-induced proinflammatory effects on microglia, and S1P suppressed the anti-inflammatory effect of ADSC-CM. This suggests that LPS-mediated microglial activation is countered by ADSC-CM through the modulation of sphingosine kinase/S1P signalling.

\section{Introduction}

$\mathrm{T}$ HE FIRST LINE OF DEFENSE in the central nervous system (CNS) is represented by microglial cells, the tissueresident macrophages, which play a primary role in promoting proinflammatory and antiviral activities [1]. Under physiological conditions, microglia is present with a ramified appearance, called "resting" state. The resting microglial cell is characterized by a small cell body with elaborated thin membrane processes, which send multiple branches and ex- tend in all directions, and low expression of several signalling molecules [2]. These signals are able to act in an autocrine manner, after binding to appropriate receptors expressed on microglial cells [3]. Once a pathological event (such as brain damage or neuroinflammatory stimuli) occurs, microglial cells, as immune sentinels, are intensely involved and undergo morphological, phenotypic, and functional changes. These microglial responses include cell shift from ramified to amoeboid morphology, secretion of proinflammatory mediators (such as cytokines and chemokines), directed migration

\footnotetext{
${ }^{1}$ Laboratory of Experimental Neurosurgery and Cell Therapy, Neurosurgery Unit, Fondazione IRCCS Ca'Granda Ospedale Maggiore Policlinico, University of Milan, Milan, Italy.

${ }^{2}$ Department of Medical Biotechnology and Translational Medicine, LITA-Segrate, University of Milan, Milan, Italy.

${ }^{3}$ Istituto Nazionale di Genetica Molecolare "Romeo ed Enrica Invernizzi," Milan, Italy.

${ }^{4}$ Division of Rheumatology, Istituto Gaetano Pini, Milano, Italy.

${ }^{5}$ Division of Pathology, Fondazione IRCCS Cà Granda Ospedale Maggiore Policlinico, University of Milan, Milan, Italy.

${ }^{6}$ Department of Health Sciences and Industrial and Information Engineering, University of Pavia, Pavia, Italy.

${ }^{7}$ Istituto Image, Milan, Italy.

*These authors contributed equally to this work and are considered co-first authors.

${ }^{\dagger}$ These authors contributed equally to this work.
} 
along a chemical gradient (i.e., chemotaxis), proliferation, phagocytic activity, and also nerve repair [4]. Uncontrolled or prolonged inflammation and microglia activation may have deleterious effects within the CNS and are involved in the pathogenesis of several neurodegenerative diseases [5]. This piece of evidence makes microglia activation an attractive target to study neuroinflammation and develop new therapeutic strategies.

Among the multiple regulatory signals of microglia, sphingosine-1-phosphate (S1P) has emerged as a critical one, in both physiological and pathological conditions. Indeed, this bioactive sphingoid, derived from sphingolipid metabolism, is relevant to the neuroprotective effects of microglia, as well as to the etiology, course, and treatment of neuroinflammation and neurodegenerative disorders [68]. S1P, synthesized from sphingosine ( $\mathrm{Sph}$ ) and ATP by sphingosine kinases (SphKs), exerts biological essential roles, including the regulation of cell proliferation, migration, fate, and immunity, predominantly through five specific G-protein-coupled receptors (S1PR1-5). As in other CNS cells, microglia can express a range of S1P receptors, including S1P1-3 and S1P5, and this expression is dynamically regulated upon activation [9-12]. S1PR activation can be crucial to activating immune cells, including microglia [11], and this can contribute to neurogenesis regulation [13]. SphKs were reported to regulate the microglial production of inflammatory signals $[9,11,14]$, and extracellular S1P has been shown to act as a powerful chemoattractant to the sites of injury [15] and increase the release of proinflammatory cytokines from activated microglia [11]. Furthermore, increased microglial activation in experimental autoimmune encephalomyelitis in CNS cell lineages was reduced by S1P1 deletion and administration of the S1P1 indirect antagonist FTY720 [16], indicating that S1P1 can control microglial activation and suggesting that microglial S1PRs are involved in the pathogenesis of neurodegenerative diseases. In agreement, FTY720 reduced microglial recruitment into lesions, activation, and cytokine production in rodent cerebral ischemic lesions, traumatic brain injury, and demyelination models [17-20].

In the last decade, a big effort in different fields, including basic research, preclinical studies, and regenerative medicine, has been made to understand the properties and regenerative abilities of human adipose tissue that rely upon adipose mesenchymal stem cells (ADSCs). ADSCs possess not only multilineage differentiation capacity [21], ability to homing to areas of injury [22], and in vivo integration and regeneration [23] but are also recognized as crucial players in the modulation of the inflammatory state. Indeed, adipose tissue exhibits pleiotropic immune regulatory activities mediated by complex mechanisms. These activities lead to the functional inhibition of different immune cell subpopulations of the innate and adaptive immunity through the release of soluble paracrine factors as well as direct cell-tocell interactions $[24,25]$. Moreover, fat tissue is an important source of secreted restorative growth factors [26] able to repair neural damage [27].

ADSCs can be isolated from adipose tissue biopsies by several protocols, different in time to digestion, enzyme type and concentration, and in culture media $[28,29]$. In addition, nonenzymatic procedures have been described [30-32]. In this field, an innovative system, named Lipogems, was recently developed and provides a nonexpanded, ready-to-use fat product $[33,34]$. This system uses mild mechanical forces in a completely closed system, thus avoiding enzymes, additives, and other manipulations. This innovative enzyme-free technology was developed to process variable amounts of lipoaspirates, resulting in a nonexpanded adipose tissue product that contains viable and functional human ADSCs [33,35].

In the last years, safety and efficacy of implanted ADSCs have been investigated in different animal models, and promising preclinical studies with good perspectives for translational approaches are underway. Increasing evidence in animal models of stroke [36,37], traumatic brain injury [38] and spinal cord injury [39], demonstrates that ADSCs play a crucial role in the repair of CNS damage, by stimulating neurogenesis and exerting neuroprotective effects $[40,41]$. A growing body of evidence indicates the potential therapeutic capacity of ADSCs in a variety of diseases as amyotrophic lateral sclerosis, Parkinson's disease, autoimmune diseases, and multiple sclerosis, highlighting the ability of ADSCs to reduce inflammatory states and induce beneficial effects [42].

Despite this, little is known on whether ADSCs exert their beneficial roles by affecting the microglial cell activity, and the possible role of S1P in these effects remains uninvestigated. In this study, we tested the anti-inflammatory role of human ADSC secretome on the N9 microglial cell line and the possible involvement of S1P signalling in this effect. To this purpose, we triggered an inflammatory response in vitro by stimulating microglia with lipopolysaccharide (LPS) and investigated whether ADSC-conditioned media (CM) might have any influence on microglia activation, in terms of cytokine production, cell viability, proliferation, and chemotaxis. Finally, we evaluated the metabolism, extracellular release, and effects of S1P on LPS-induced microglia activation, in the absence or presence of ADSC-CM.

\section{Materials and Methods}

\section{Patient eligibility}

The protocol was reviewed and approved by the Internal Institute Board, and the study was performed according to the amended Declaration of Helsinki. Liposuction aspirates from subcutaneous adipose tissues were obtained from six subjects (Table 1), two males and four females, aged between 35 and 60 years, undergoing elective plastic surgical procedures at the Image Institute (Milan, Italy). Before sample collection, a written informed consent was obtained from all patients.

\section{Adipose tissue samples}

Specimens of fat from the abdomen region were collected by a lipoaspirate technique. All specimens were verified for the presence of human immunodeficiency virus 1 and 2, hepatitis C virus, hepatitis B virus, and cytomegalovirus. Fat tissues were serially processed to obtain two different aliquots: a first unprocessed lipoaspirate (ASP) specimen and a second processed sample, obtained by treating the ASP with the Lipogems ${ }^{\circledR}$ device (GEMS). Briefly, lipoaspirated tissues were introduced and shaken into the Lipogems device (LIPOGEMS International SRL, Milan, Italy), containing beads that allow the fragmentation of the fat tissue and the removal of red blood cells and oil residues $[34,43]$. An aliquot of both 
Table 1. Clinical Details of Patients

\begin{tabular}{lclclcc}
\hline Number & Sample ID & Sex & Age (years) & BMI & Surgery & Region \\
\hline 1 & ADSC02 & Female & 35 & 27.68 & Liposuction & Abdomen \\
2 & ADSC04 & Female & 54 & 25.39 & Liposuction & Abdomen \\
3 & ADSC06 & Male & 48 & 24.22 & Liposuction & Abdomen \\
4 & ADSC07 & Female & 60 & 22 & Liposuction & Abdomen \\
5 & ADSC08 & Female & 39 & 24.9 & Liposuction & Abdomen \\
6 & ADSC15 & Male & 42 & 27.78 & Liposuction & Abdomen \\
\hline
\end{tabular}

ADSC, adipose mesenchymal stem cells.

ASP and GEMS tissue samples $(0.5 \mathrm{~mL})$ was frozen dry at $-80^{\circ} \mathrm{C}$ for enzyme-linked immunosorbent assay (ELISA), and an aliquot $(0.5 \mathrm{~mL})$ was processed for ADSC isolation by selective culture conditions as described below.

\section{ELISA on adipose tissues}

The frozen adipose tissues were homogenized in ice-cold lysis buffer using a homogenizer. After a 10-min incubation at $4^{\circ} \mathrm{C}$ with constant rotation, the homogenate was centrifuged (300 $\mathrm{g}, 10 \mathrm{~min}$ ) and the subnatant (whole tissue extract) below the lipid cake was aspirated and denatured. Total protein concentrations of the whole tissue extracts were measured using the Bradford method. Subsequently, both ASP and GEMS tissue samples were analyzed by Multianalyte Elisa Array-Human Inflammatory Cytokines (MOHE004A; Sa Bioscience, a Qiagen company, Manchester, UK) following the manufacturer's protocols.

\section{ADSC culture}

ADSCs from both ASP and GEMS tissues were obtained as previously described $[23,44]$. Briefly, tissues were washed with saline D-PBS and centrifuged for $10 \mathrm{~min}$ at $920 \mathrm{~g}$ at room temperature (RT) to recover the stromal vascular fraction, which was immediately plated in T25 flasks in Dulbecco's modified Eagle's medium/Nutrient F-12 Ham (DMEM/F12) supplemented with $10 \%$ fetal bovine serum (FBS) (Euroclone, Milan, Italy) and $1 \%$ penicillin and streptomycin solution (Sigma-Aldrich, Milan, Italy), optimized for the selective growth of ADSCs. The ASP- and GEMS-ADSCs were routinely seeded at $2 \times 10^{4}$ cells $/ \mathrm{cm}^{2}$ in T75 flasks and passed weekly. Cell viability was assessed by the Trypan blue (Life Technologies, Carlsbad, CA) dye-exclusion assay. Cells were passaged at a density of $75 \%-90 \%$ for $\sim 14$ days in culture and maintained in culture through passage 4 . Cells were counted in three microscopic fields in each well and expressed as a percentage of the total number of cells.

\section{FACS analysis}

ASP- and GEMS-ADSCs were evaluated for the expression of mesenchymal, hematopoietic, endothelial, and immunological markers: anti-human CD14-PE, CD31-PE, CD34-PE, CD45-FITC, CD73-PE, HLA-DR-FITC (BD Pharmingen, San Jose, CA), and CD105-FITC (AbDSerotec, Raleigh, NC). Briefly, $5 \times 10^{4}$ cells/tube were stained with fluorochrome-conjugated monoclonal antibodies and incubated for $15 \mathrm{~min}$ at RT in the dark. Samples were centrifuged at $300 \mathrm{~g}$ for $5 \mathrm{~min}$, washed twice with D-PBS and then fixed with $4 \%$ paraformaldehyde (PFA). Isotypematched mouse immunoglobulins were used as control. At least $5 \times 10^{3}$ events were acquired for each sample. Nonviable cells were excluded by physical gating. For data acquisition, a FACS Canto II (BD Pharmingen) with DIVA software was used, whereas the analysis of the data was performed using the Cell Quest software (BD Pharmingen).

\section{ADSC-CM collection and preparation}

ASP- and GEMS-ADSCs were plated at density of $7 \times 10^{5}$ cells $/ \mathrm{cm}^{2}$ for 7 days and supernatants were collected from both cultures, centrifuged for $10 \mathrm{~min}$ at $500 \mathrm{~g}$, and stored at $-20^{\circ} \mathrm{C}$ for the subsequent experiments. The final supernatant is referred as CM.

\section{Microglial cell culture}

The murine microglial cell line N9 was cultured in the IMDM medium supplemented with $4 \mathrm{mM}$ glutamine, $25 \mathrm{mM}$ HEPES (Invitrogen, Carlsbad, CA), 1\% penicillin/streptomycin solution, and 5\% FBS. This culture condition is referred in the text as the basal medium (BM). The cells were grown at $37^{\circ} \mathrm{C}$ in a humidified incubator in $95 \%$ air- $5 \% \mathrm{CO}_{2}$ and were split once every 3 days at $4 \times 10^{3}$ cells $/ \mathrm{cm}^{2}$.

\section{Microglial cell treatments}

Microglial cells were challenged for $48 \mathrm{~h}$ in the BM with $3 \mu \mathrm{g} / \mathrm{mL}$ LPS (from Escherichia coli, serotype 055:B5; SigmaAldrich) alone, to induce their activation, or in the presence of ASP-CM or GEMS-CM (1:4, v/v). Therefore, microglial cells were divided into the following six experimental groups: (1) Control group (CTR): BM incubation; (2) LPS-treated group (LPS): incubation with $3 \mu \mathrm{g} / \mathrm{mL}$ LPS in BM; (3) ASP-CM group: incubation in ASP-CM; (4) ASP-CM+LPS group (LPS+ASP-CM): incubation in ASP-CM supplemented with $3 \mu \mathrm{g} / \mathrm{mL}$ LPS; (5) GEMS-CM group: incubation in GEMSCM; (6) GEMS+LPS group: (LPS+GEMS-CM): incubation in GEMS-CM supplemented by $3 \mu \mathrm{g} / \mathrm{mL}$ LPS.

In the case of S1P treatment, a stock solution of S1P (100 mM; Enzo Life Sciences, Farmingdale, NY) was prepared in fatty acid-free bovine serum albumin $(4 \mathrm{mg} / \mathrm{mL}$ in BM). For N,N-dimethylsphingosine (DMS) and FTY720 treatments, stock solutions of $5 \mathrm{mM}$ DMS (Enzo Life Sciences) and $10 \mathrm{mM}$ FTY720 (Cayman Chemicals, Ann Arbor, MI) were prepared in absolute ethanol. At the time of the experiments, stock solutions were administered to cells at the following final concentrations: $200 \mathrm{nM}-1 \mu \mathrm{M}$ for S1P, $100 \mathrm{nM}$ for FTY720, and $1 \mu \mathrm{M}$ for DMS, for the indicated 
periods of time. At the used concentrations, ethanol had no effect on cell growth and viability.

\section{Assessment of ADSC and microglia viability and proliferation}

The viability and proliferation of ASP- and GEMS-ADSCs were assessed by trypan blue staining. Briefly, cells were plated at a density of $2 \times 10^{4}$ cells $/ \mathrm{cm}^{2}$ in 48 -well culture plates (Corning Life Sciences, New York, NY). After 14 days of culture, cells were harvested, counted, and seeded at the same initial density for next passage count. The total number of dead and viable cells was counted at each passage by Trypan Blue dye-exclusion assay in a Fuchs-Rosenthal chamber, and the percentage of viability was assessed by the following formula: viable cell number/(viable cell number + dead cell number) $\times 100$. Growth curves were obtained by counting the number of viable cells at each passage and calculating the cumulative population at each passage [45].

The effect of ADSC-CM and/or S1P modulators on microglial proliferation was determined by assessing ${ }^{3} \mathrm{H}$-thymidine (PerkinElmer, Boston, MA) incorporation into DNA [46]. Cells were plated $\left(2 \times 10^{4} / \mathrm{cm}^{2}\right)$ in $35-\mathrm{mm}$ Falcon dishes in $\mathrm{BM}$ and grown for $24 \mathrm{~h}$. Cells were then treated with ADSC$\mathrm{CM}$ and/or S1P modulators (as described above) for $48 \mathrm{~h} .{ }^{3} \mathrm{H}-$ thymidine $(1 \mu \mathrm{Ci} / \mathrm{mL})$ was added to each plate $12 \mathrm{~h}$ before cell harvesting. At the end, cells were harvested with phosphate-buffered saline, and the thymidine incorporation in trichloroacetic-insoluble material was determined by liquid scintillation counting.

\section{Microglial cell immunofluorescence}

To confirm microglial lineage and the effect of the different treatments on its activation, we assessed the expression of ionized calcium-binding adapter molecule 1 (IBA1) and CD68 by immunofluorescence analyses.

Microglial cells cultured for 1 day on permanox chamber slide at the concentration of $2.5 \times 10^{4} \mathrm{cell} / \mathrm{cm}^{2}$ were treated with LPS alone or in combination with ADSC-CM. After $48 \mathrm{~h}$ at $37^{\circ} \mathrm{C}$, the cells were fixed with $4 \%$ PFA $(15 \mathrm{~min}$, RT). To avoid quenching, microglia were treated with $0.1 \mathrm{M}$ glycine (10 min, RT). Subsequently, the samples were permeabilized with $0.1 \%$ Triton X-100 for $15 \mathrm{~min}$. The following primary antibodies were applied overnight at $4^{\circ} \mathrm{C}$ : mouse anti-IBA1 (1:500) and mouse anti-CD68 (1:400), (both purchased from Santa Cruz Biotechnology, Inc., Heidelberg, Germany). Cells were then incubated with Alexa488 conjugated secondary antibody (1:1,000; Life Technologies) at RT for $45 \mathrm{~min}$, washed, and the nuclei were counterstained with DAPI (Life Technologies). The sample was mounted with ProLong ${ }^{\circledR}$ Gold Antifade Mountant (Life Technologies) and images were captured using a Leica TCS SP5 confocal microscope (Leica Microsystems, Wetzlar, Germany). Cells were counted in three microscopic fields in each well (three wells/treatment) and expressed as a percentage of the total number of cells. Each treatment was performed in triplicate.

\section{Chemotaxis of microglial cells in presence of ASP- and GEMS-CM}

Chemotaxis of microglia was performed using the modified Boyden chemotaxis chamber assay $(8.0 \mu \mathrm{m}$ pore size; Falcon,
Corning, New York, NY). Briefly, microglia $\left(5 \times 10^{4}\right.$ cells/ $\mathrm{mL}$ ) were suspended in $\mathrm{BM}$, and $200 \mu \mathrm{L}$ of the cell suspension was added to the top compartment of the chamber. LPS was added to the lower chamber, in the absence or presence of ASP- or GEMS-CM and/or FTY720 or S1P. The chambers (set up in triplicate) were incubated for $48 \mathrm{~h}$. At the end, nonmigrated cells on the upper side of the filter membrane were gently wiped off with a cotton swab. Subsequently, the filters were removed, and cells were fixed in methanol, stained with hematoxylin/eosin, and then scanned with the $\operatorname{EVOS}^{\circledR} \mathrm{FL}$ Auto Imaging System, using a $4 \times$ objective. Multiple images were then tiled and stitched together using the ImageJ software by the plugin Stitching. Microglia cells migrated in the lower compartment of the chamber and were stained with Calcein AM (Life Technologies). The fluorescent dye $(1: 1,000)$ was administered directly into each well and the cells were incubated at $37^{\circ} \mathrm{C}$ for $30 \mathrm{~min}$. At the end of the incubation, the chambers were washed, acquired by using an inverted Eclipse Ti-E microscope (Nikon Instruments, Florence, Italy), and the number of migrated microglial cells was determined in the whole well by ImageJ software.

\section{ELISA on microglia medium after coincubation with ASP-CM or GEMS-CM}

Cells were seeded into 24-well plates at the density of $5 \times 10^{4}$ cells/well. After $48 \mathrm{~h}$ in the presence of different treatments (see above), the supernatants were collected, centrifuged for $10 \mathrm{~min}$ at $500 \mathrm{~g}$, and stored at $-20^{\circ} \mathrm{C}$. The supernatants were subjected to the evaluation of the expression levels of interleukin IL-10 and IL-17 by specific ELISA kits (Affymetrix eBioscence, San Diego, CA) according to the manufacturer's instructions. The absorbance at $450 \mathrm{~nm}$ was recorded using a microplate reader. Data analysis was performed by SP2000 Manager software.

\section{S1P metabolism and extracellular release in microglial cells}

To evaluate S1P metabolism and extracellular release, pulse studies with $\left[\mathrm{C} 3-{ }^{3} \mathrm{H}\right]$-sphingosine $\left({ }^{3} \mathrm{H}-\mathrm{Sph}\right.$; PerkinElmer, Boston, MA) were performed as previously described $[47,48]$. Briefly, cells were incubated with ${ }^{3} \mathrm{H}-\mathrm{Sph}(20 \mathrm{nM}, 0.4 \mu \mathrm{Ci} / \mathrm{mL})$ in the S1P trapping medium for $1 \mathrm{~h}$. At the end, media were collected, and cells were harvested. Total lipids were extracted from cells at $4{ }^{\circ} \mathrm{C}$ and partitioned as previously reported [49]. After centrifugation, the upper alkaline aqueous phase, containing S1P, was evaporated under a nitrogen stream and counted for radioactivity by liquid scintillation. Extracellular $\mathrm{S} 1 \mathrm{P}$ was extracted from the pulse medium and partially purified by two-step partitioning, at first in alkaline conditions. Then a back extraction of the aqueous phase was carried out in acidic conditions [49]. The final organic phase, containing $\mathrm{S} 1 \mathrm{P}$, was evaporated under a nitrogen stream. The fractions containing cellular and extracellular S1P were submitted to high-performance thin layer chromatography (HPTLC) on silica gel plates, using n-butanol/acetic acid/water (3:1:1, v/v/ v) as solvent system. Standard ${ }^{3} \mathrm{H}-\mathrm{S} 1 \mathrm{P}$ was chromatographed on the same plate and used as internal standard. At the end of the chromatography, HPTLC plates were submitted to digital autoradiography (Beta-Imager 2000; Biospace, Paris, France), 
and S1P was quantified by the beta vision analysis software provided with the instrument.

\section{Statistical analysis}

Results are expressed as the means $\pm \mathrm{SD}$ of three independent assays. The comparisons between two groups were undertaken by using the unpaired Student's $t$-test. A $P$ value $<0.05$ was considered statistically significant.

\section{Results}

\section{ASP and GEMS tissues express different levels of inflammatory cytokines}

As shown in Fig. 1A and B, GEMS tissue color was clearer than the ASP one. The ELISAs of a focused panel of 12 proteins related to inflammation (Fig. 1C) revealed that the levels of several cytokines were significantly different in GEMS and ASP (Fig. 1C). In particular, the content of some inflammatory cytokines (including interleukin [IL-]1 $\beta$, IL-6, IL-8, and tumor necrosis factor-alpha [TNF- $\alpha]$ ) in the GEMS tissue was significantly lower than that in ASP.

\section{Human ADSCs isolated from ASP and GEMS tissues exhibit a mesenchymal stem cell phenotype and proliferative properties}

To evaluate if the phenotype and growth properties of ASP- and GEMS-ADSCs were different, we analyzed the morphology and growth curve during first passages.
Once seeded in BM, both ADSCs grew adherent to plastic, and exhibited a fibroblast-like morphology (Fig. 2A, B). Cell growth analyses demonstrated that both ASP- and GEMS-ADSCs started to proliferate 7-10 days after plating, and continued to propagate along with passages (Fig. 2C). Of note, GEMS-ADSCs showed a higher proliferation rate than ASP-ADSCs (Fig. 2C), and the number of viable cells from ASP was found to be significantly lower than that from GEMS (Fig. 2D).

To characterize the immunological phenotype of ASPand GEMS-ADSCs, we next analyzed the expression of different surface markers. Our results show that both ASPand GEMS-ADSCs highly expressed the mesenchymal stem cell (MSC) markers CD73 and CD105 (Fig. 2E, F), but did not express hematopoietic (CD34 and CD45), leukocyte (CD14 and HLA-DR), and endothelial (CD31) markers, thus excluding the contamination by different cell types, including lymphocytes and monocytes.

\section{ADSC-CM inhibit LPS-induced activation of microglial cells}

We then investigated whether ADSC-CM were able to affect microglial activation induced by LPS, a wellrecognized inflammatory stimulus. In the presence of LPS, morphological analyses of microglial cells showed that the ramified morphology of cell resting state (Fig. 3A) changed into an amoeboid morphology, the typical morphological state of activated microglial cells (Fig. 3B). After treatment with ASP-CM or GEMS-CM alone, microglial cells maintained

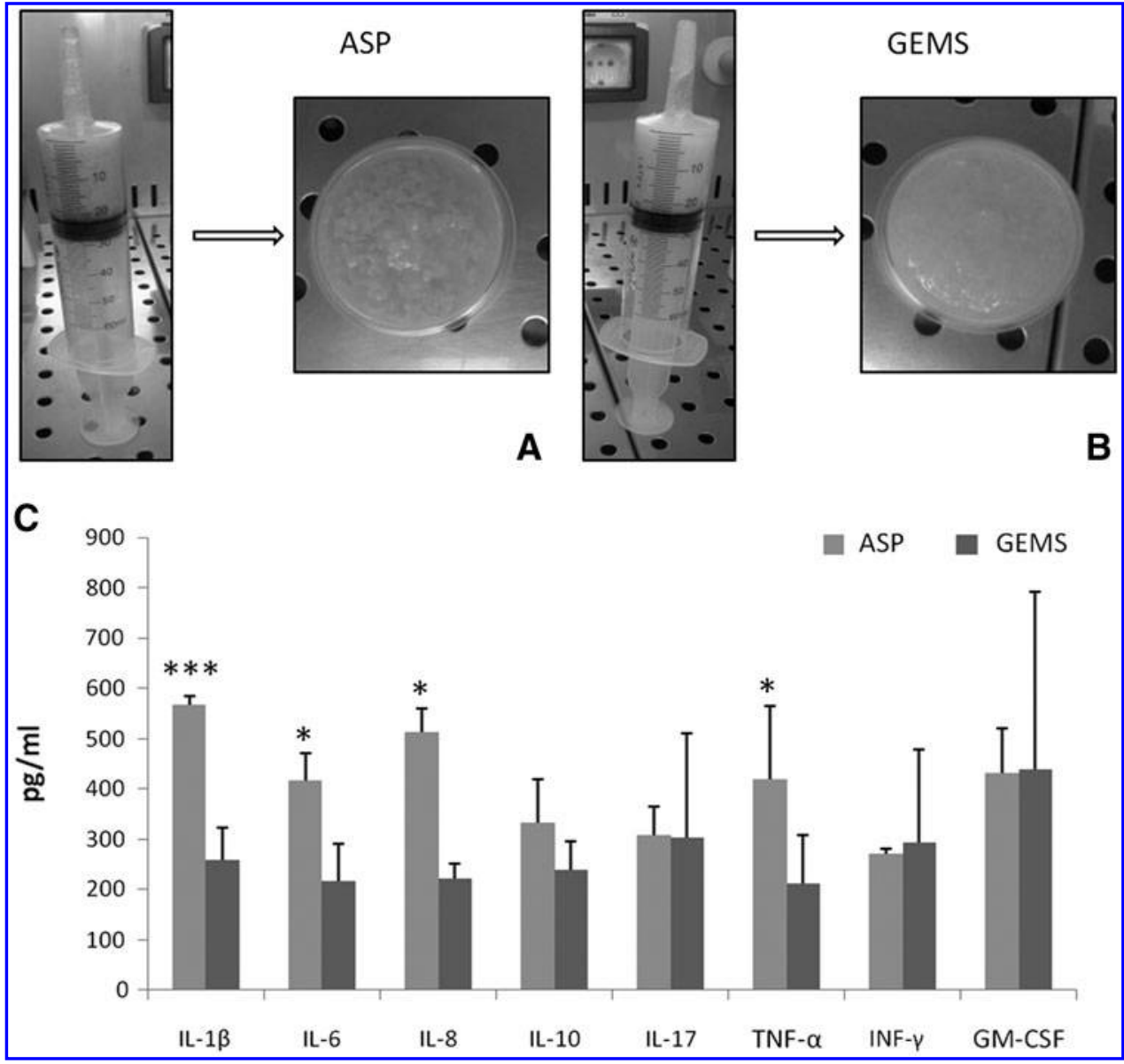

FIG. 1. Characterization of ASP and GEMS adipose tissue. Photomicrographs of ASP (A) and GEMS (B) adipose tissue, during transfer from a syringe into a dish. (C) Profile levels of different human inflammatory cytokines obtained by ELISA in ASP and GEMS tissues. $* P<0.05$; $* * * P<0.001$. ASP, lipoaspirate; ELISA, enzymelinked immunosorbent assay; GEMS, Lipogems. 

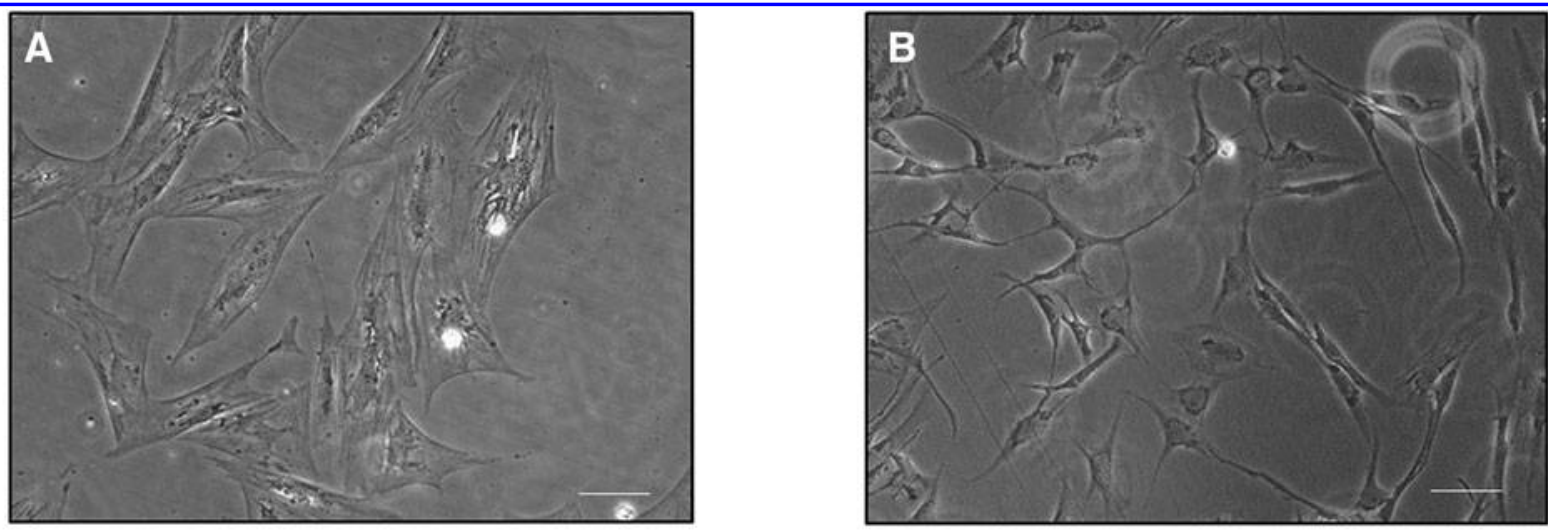

C

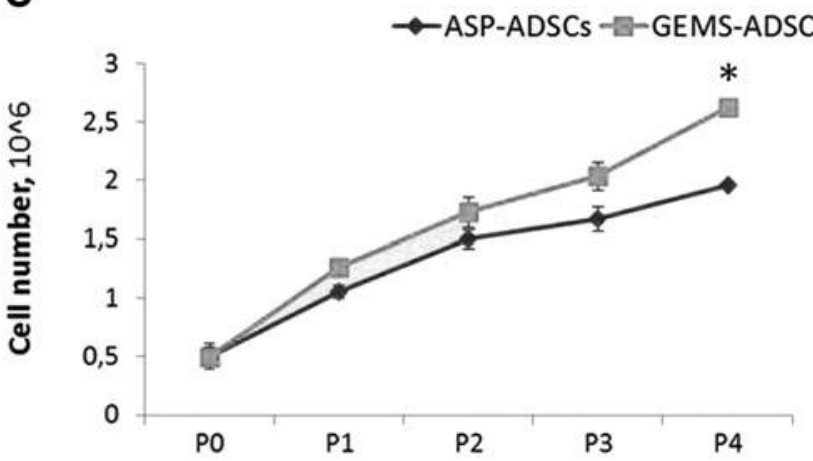

E

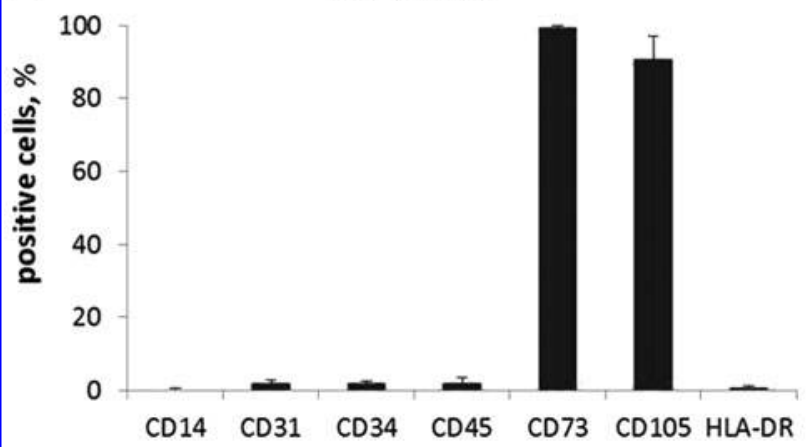

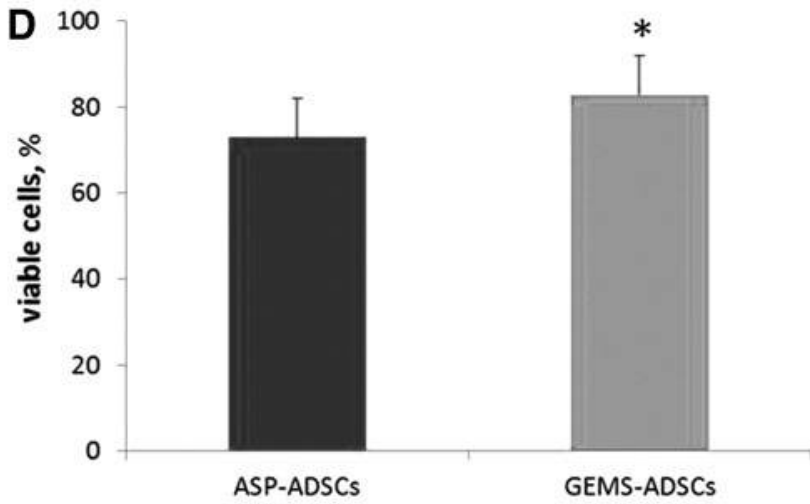

$\mathbf{F}$
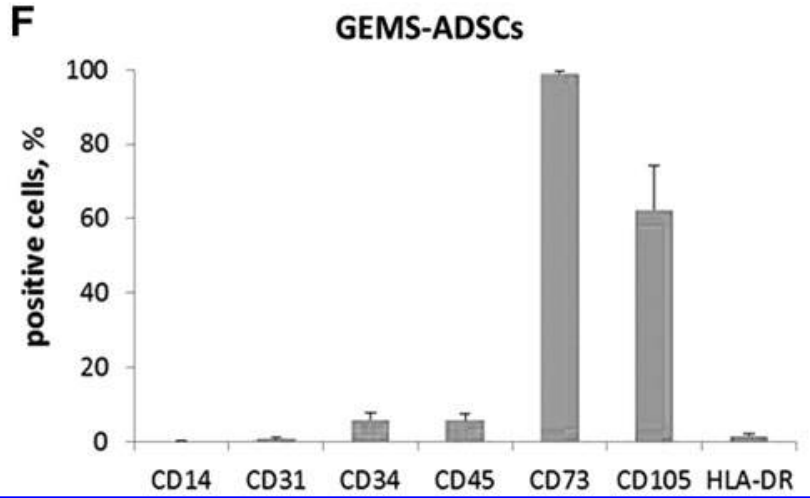

FIG. 2. Characterization of ASP- and GEMS-ADSCs. Photomicrographs of ASP-ADSCs (A) and GEMS-ADSCs (B) are shown at passage $4($ scale bar, $100 \mu \mathrm{m})$. Cell growth and viability analyses of ASP- and GEMS-ADSCs cultured in BM are shown in $(\mathbf{C}, \mathbf{D})$, respectively. Immunophenotypic analyses of multiple surface epitopes in ASP- and GEMS-ADSCs are shown in $(\mathbf{E}, \mathbf{F}) .{ }^{*} P<0.05$. ADSC, adipose mesenchymal stem cells; BM, basal medium.

their resting morphology (Fig. 3C, D). In contrast and of interest, the morphology of microglial cells stimulated with LPS combined with either ASP-CM or GEMS-CM showed the presence of both amoeboid and ramified cells, with the predominance of the ramified morphology (Fig. 3E, F). Thus, both ASP- and GEMS-CM were able to reduce/inhibit LPS-induced changes in microglial morphology.

Then, to assess the expression markers of resting/activated microglia, we performed immunofluorescent analyses. In all experimental conditions, DAPI counterstaining showed that microglial cells exhibited IBA1-immunoreactivity in a similar manner (Fig. 3G-L). On the contrary, the expression of CD68, a recognized marker for activated phagocytic microglia, was different among the tested treatments. Indeed, CD68 was expressed at very low (if any) levels before microglial LPS activation (Fig. 3M), as well as after ASP- or GEMSCM treatment (Fig. 3O, P), but prominently increased after LPS treatment (Fig. 3N). Of relevance, treatments with both types of ADSC-CM were able to suppress the LPS-induced expression of CD68 (Fig. 3Q, R). This indicates that ADSC$\mathrm{CM}$ were both able to potently inhibit the upregulation of functional phagosomes in LPS-treated microglia.

Our investigation proceeded with the aim of assessing if ADSCs were able to affect the microglia production of inflammation-related ILs. As shown in Fig. 3S, T, after $48 \mathrm{~h}$ of culture, resting microglia (CTR) released both IL-10 and IL-17 in the medium. As expected, LPS exposure increased the extracellular level of both cytokines, with a high significance for 


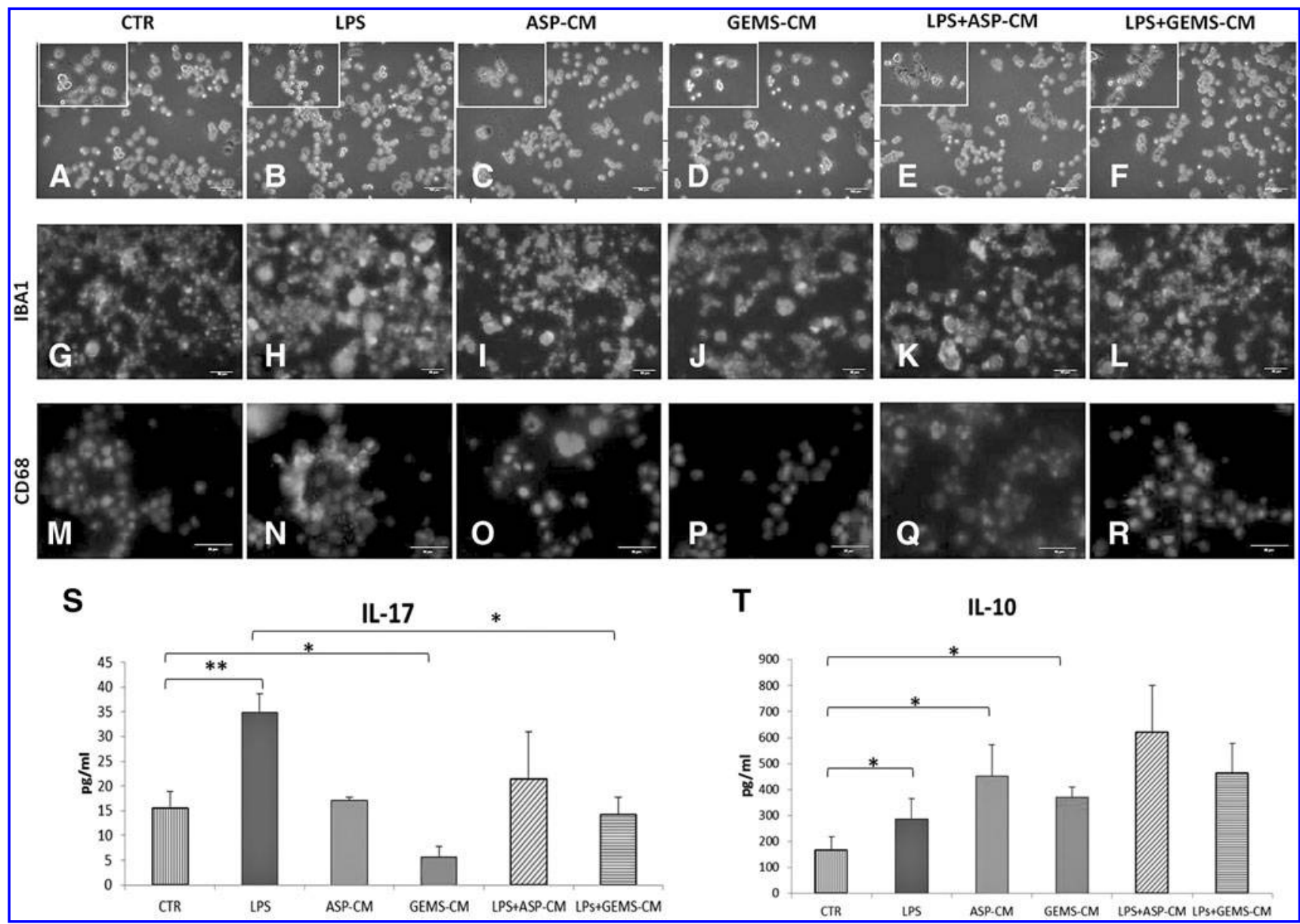

FIG. 3. ADSC-CM treatment inhibits LPS-induced activation in microglial cells. (A-F) Morphological appearance of activated microglial cells prior and after treatments with ADSC-CM. Scale bar, $100 \mu \mathrm{m}$; an image enlargement is shown in the upper left box. (G-R) Immunofluorescence analyses for IBA1 (G-L) and CD68 (M-R) expression in microglial cells prior and after the indicated treatments. Microglia nuclei were stained with DAPI. Scale bar, $50 \mu \mathrm{m}$. Production of IL-17 (S) and IL-10 (T) performed by ELISA on microglial supernatants after LPS and/or ADSC-CM treatment. Data are the mean \pm SD of at least three independent experiments. $* P<0.05$; $* * P<0.01$. CM, conditioned media; IBA1, ionized calcium-binding adapter molecule 1; IL, interleukin; LPS, lipopolysaccharide.

the IL-17 one. Of note, both ADSC-CM alone affected the basal release of IL-17 and IL-10 in LPS-treated microglia. Indeed, in the presence of LPS and ASP- or GEMS-CM, a significant decrease of the proinflammatory IL-17 and a significant upregulation of the anti-inflammatory IL-10 occurred (Fig. 3S, T).

\section{ADSC-CM inhibit LPS-induced proliferation and chemotaxis of microglia}

We next investigated the effect of CM on microglia viability, growth, and chemotaxis prior and after LPS treatment (Fig. 4). In the used experimental conditions, LPS treatment, either alone or in combination with ASP- or GEMS-CM had no effect on microglia survival. Indeed, after $48 \mathrm{~h}$ of different treatments, microglia viability was higher than $95 \%$ in all cases (Fig. 4A). The results of the proliferation analyses demonstrated that microglial proliferation was significantly enhanced by LPS (Fig. 4B), and the treatment with either ASP- or GEMS-CM was able to counteract the LPS-induced proliferative effect. Indeed, the proliferation of microglial cells cotreated with LPS and ASP-/GEMS-CM did not differ from untreated cells (Fig. 4B).
In further studies, microglial chemotaxis was investigated. We first found that, in resting conditions, N9 microglial cells were able to spontaneously migrate, and this migration was significantly promoted by LPS (Fig. 4C, D). Both ASP- and GEMS-CM treatments exerted a significant antichemotactic effect on LPS-induced microglia migration. In fact, the migration of microglial cells treated with LPS together with ADSC-CM was significantly decreased when compared with that of cells treated with LPS alone (Fig. 4C). Hematoxylin/eosin staining confirmed these trends, in that event microglial migration was lower in CTR condition than after LPS stimulation (Fig. 4C). The quantification of migrated microglial cells revealed that the LPS-induced chemotactic activity was significantly reduced by both ADSCCM (Fig. 4D).

\section{S1P is involved in the proliferative behavior of LPS-stimulated microglia}

To investigate whether LPS-induced proliferation depends on the SphK activity, microglial cells were exposed to LPS in the absence or presence of DMS, a potent inhibitor 

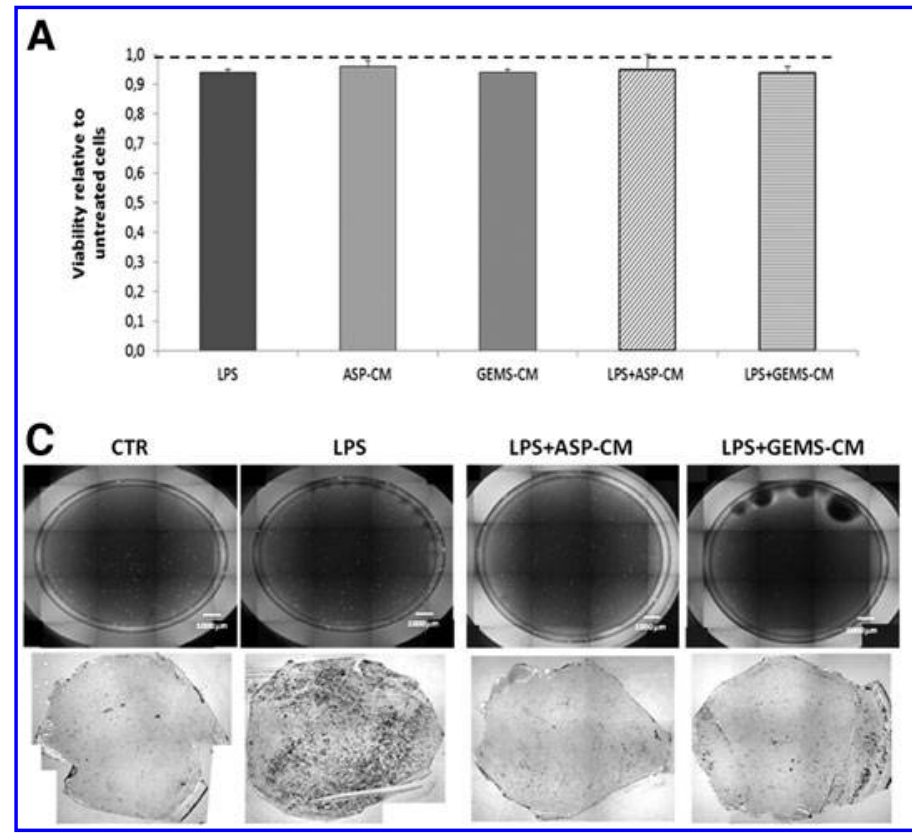
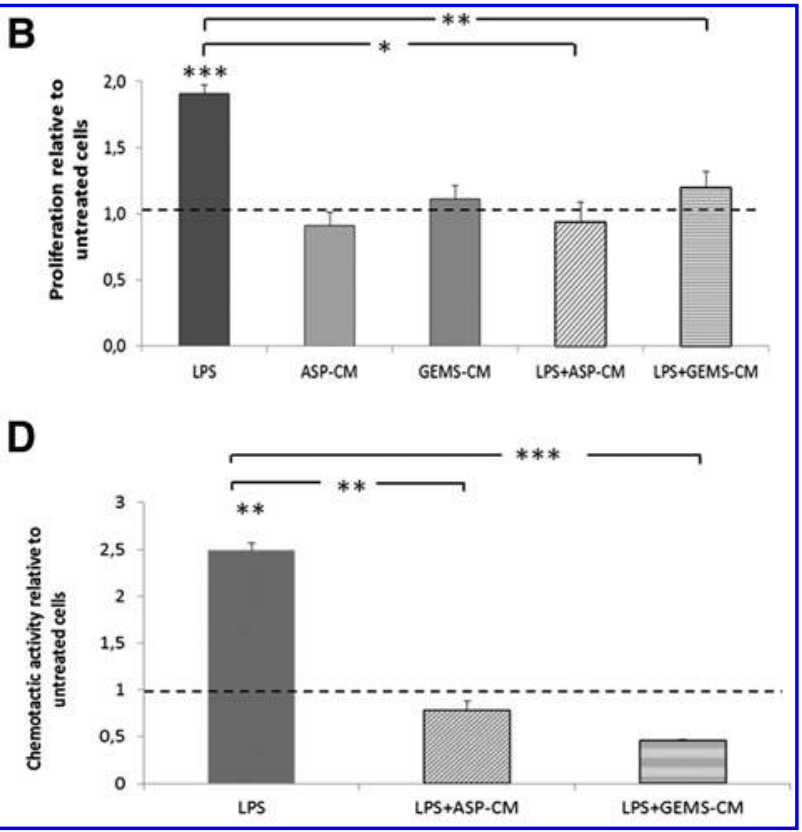

FIG. 4. ADSC-CM inhibits microglial proliferation and chemotaxis. Cell viability (A) and proliferation (B) of microglial cells treated with LPS alone or in combination with ADSC-CM. Photomicrographs (scale bar, $1 \mathrm{~mm}$ ) of the chemotaxis assay showing transwells and their inserts (C), and quantification of the migrated cells (D) in basal condition (CTR), after LPS stimulus alone, or in combination with ADSC-CM. Dotted line represents the value of untreated cells, in basal condition (CTR). $* P<0.05 ; * * P<0.01 ; * * * P<0.001$.

of SphKs. As shown in Fig. 5A, the administration of DMS significantly decreased the LPS-induced incorporation of tritiated thymidine into microglial cells, suggesting that the SphK activity and thus S1P formation are required by LPS to exert its growth promoting effect on microglia. In support, cell exposure to S1P induced a potent proliferative effect in both the absence and presence of ADSC-CM (Fig. 5B). This indicates that $\mathrm{S} 1 \mathrm{P}$ is able to stimulate microglial proliferation, even in the presence of ADSC-CM. Notably, similar results were obtained at $200 \mathrm{nM}$ (Fig. 5B) and $1 \mu \mathrm{M}$ (data not shown) concentration of S1P, suggesting that S1P stimulates microglial proliferation through a receptor-mediated mechanism.

\section{ADSC-CM inhibits S1P synthesis and secretion in LPS-stimulated microglia}

Aiming to evaluate the possible role of cellular and/or extracellular S1P in ADSC-CM anti-inflammatory effects on microglial cells, we investigated whether the administration

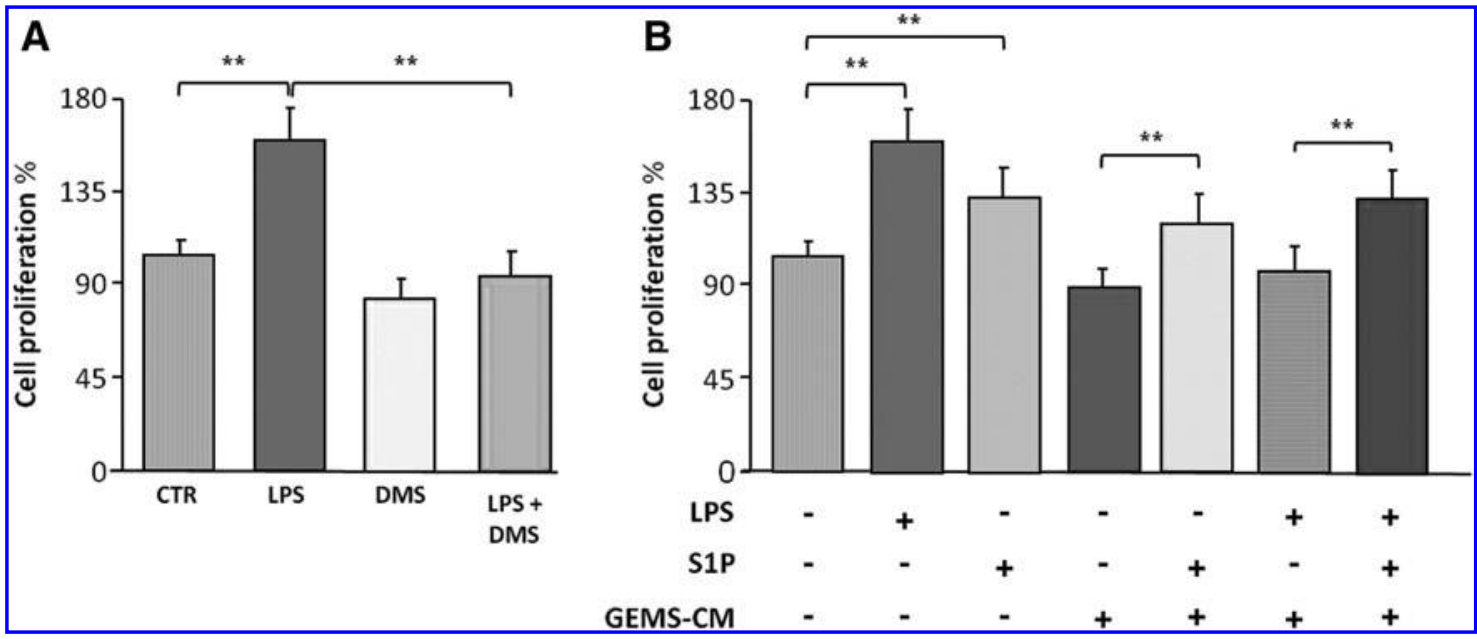

FIG. 5. Effects of DMS and S1P on microglial cell proliferation. Incorporation of ${ }^{3} \mathrm{H}$-thymidine into microglial cells after 48-h incubation in BM in the absence or presence of LPS, GEMS-CM, $1 \mu$ M DMS (A), or $200 \mathrm{nM}$ with S1P (B). Similar results were obtained with $\mathrm{ASP}-\mathrm{CM}$, as well as with $1 \mu \mathrm{M} \mathrm{S1P}$. Data are the mean \pm SD of at least three independent experiments. $* * P<0.01$. DMS, N,N-dimethylsphingosine; S1P, sphingosine-1-phosphate. 
of ADSC-CM, in the absence or presence of LPS, results in any variation of intracellular and/or extracellular S1P production by microglia. Since both metabolism and release of S1P can be evaluated after administration of radiolabeled Sph [49], microglial cells were pulsed with radiolabeled Sph, in the absence or presence of the different treatments, and radiolabeled S1P was evaluated in both cells and media. As shown in Fig. 6A, after a 2-h LPS treatment, radiolabeled S1P was significantly increased, whereas ADSC-CM alone did not affect the basal S1P value. Of relevance, ADSC-CM in combination with LPS treatment were able to significantly counteract the LPS-induced S1P production by microglia.

Of interest, after medium extraction and partitioning, radiolabeled $\mathrm{S} 1 \mathrm{P}$ was found as a medium component in both untreated and treated microglial cells. The radioactivity associated to extracellular S1P was found similar in untreated and ADSC-CM-treated cells (Fig. 6B). We also found that LPS stimulation significantly increased S1P secretion by microglia, and, most importantly, both types of
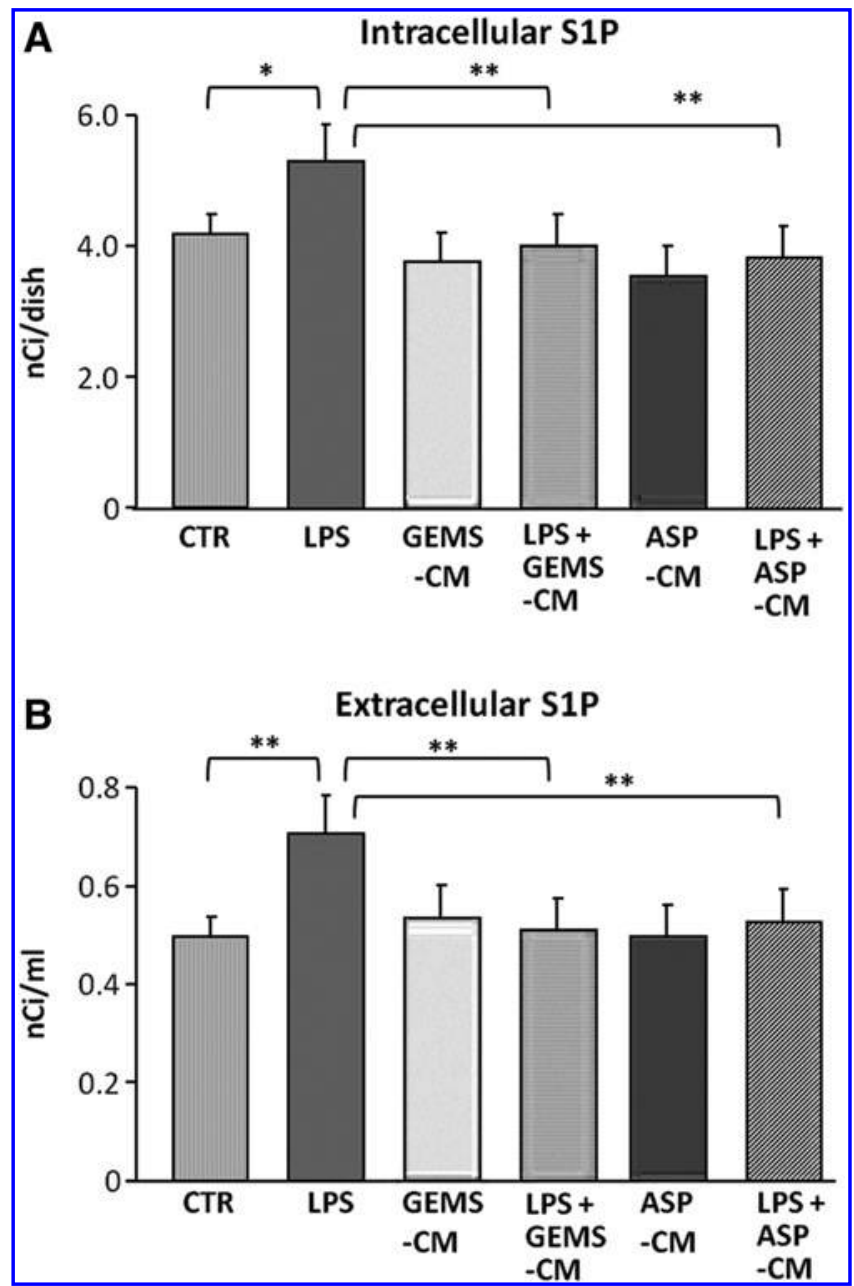

FIG. 6. Effects of LPS and ADSC-CM on S1P metabolism and extracellular release in microglia. Microglial cells were fed with $20 \mathrm{nM}{ }^{3} \mathrm{H}$-Sph for $1 \mathrm{~h}$ in the absence (CTR) or presence of LPS and/or ADSC-CM. At the end, cells and media were collected and processed as described in Materials and Methods. Radioactivity incorporation into cellular S1P (A) and extracellular S1P (B) is shown. Data are mean \pm SD of three experiments in duplicate. ${ }^{*} P<0.05$, $* * P<0.01$.
ADSC-CM were able to nullify the LPS-induced microglia release of S1P (Fig. 6B).

\section{ADSC-CM downregulate the induction of extracellular S1P pathway upon LPS-stimulated microglia}

On the basis of the above results, it was of interest to investigate whether the modulation of extracellular S1P pathway might influence ADSC-CM-induced inhibition of LPS microglial activation. To this purpose, we first tested the effect of FTY720, an S1PR functional antagonist [50,51]. We found that LPS stimulation of cell growth (as thymidine incorporation into DNA), chemotactic activity, or CD68 expression was significantly reduced by FTY720 (Fig. 7A-C). These results support that extracellular S1P, after binding to S1PRs, acts as an extracellular mediator of LPS-induced microglial activation, and FTY720 was able to inhibit this, in a similar manner to what it occurs with ADSC-CM treatments. In agreement, when LPS- and ADSC-CM-treated cells were incubated with exogenous $\mathrm{S} 1 \mathrm{P}$, a significant stimulation of microglial cell proliferation, chemotactic behavior, and CD68 expression was found (Fig. 7A-C).

\section{Discussion}

Adipose tissue and ADSCs represent one of the major research topics in regenerative medicine. A great benefit is represented by the minimally invasive accessibility to adipose tissue and its ready availability [52]. To this purpose, in our study, we investigated the inflammatory profile of tissue isolated from fast, safe, and readily available source of fat explants [35] by lipoaspirate procedure and Lipogems device. This latter new technique, derived from lipofilling surgical method [43], represents a new field of regenerative surgery, whose therapeutic criteria are based on the possibility of transferring the MSCs [53] in those damaged areas of the human body that require repair and immunomodulation. We found that adipose tissues secreted several inflammationrelated cytokines with different expression levels in two adipose sources. In particular, GEMS tissue presented a significantly lower content of some inflammatory cytokines, including IL- $1 \beta$, IL-6, IL-8, and TNF- $\alpha$, than the ASP tissue. Recent studies have shown that adipose tissue is a potent source of inflammatory cytokines by two types of cells: fat cells (mainly adipocytes) and non-fat cells [54]. As GEMS tissues were prepared by fragmentation of the fat ASP tissue, yielding a stromal vascular fraction highly enriched in pericytes and MSCs from human lipoaspirates, it is likely that the depletion of nonfat cells in GEMS-CM contributes to its low profile of inflammatory cytokines. The expression level of inflammation-related cytokines in both ADSC-CM was lower than that expressed from other human mesenchymal tissues, such as bone marrow [55], anyway.

In an effort to characterize resident ADSCs in fat tissue derivatives, it was observed that GEMS and ASP fat explants showed similar tissue architecture. In this study, we demonstrate that a subpopulation of stem cells, with mesenchymal phenotype, can be obtained from adipose tissue by both lipoaspirate and Lipogems procedures. Indeed, no difference in phenotypic profile in ADSCs obtained from GEMS or ASP tissues was observed [43]. In line with this, Bianchi and 


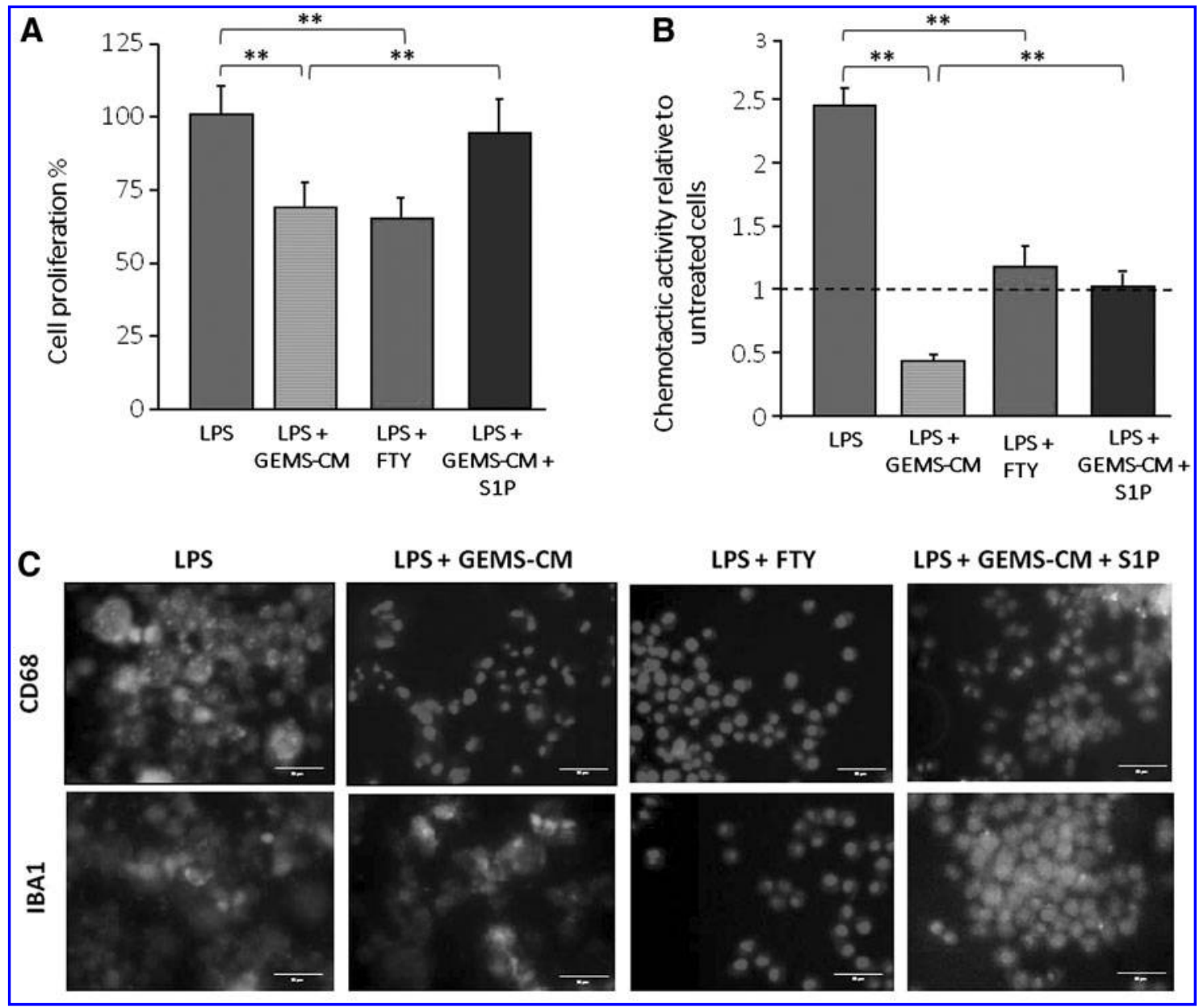

FIG. 7. Effects of FTY720 and S1P on microglia proliferation, migration, and activation. Microglial cells were incubated $48 \mathrm{~h}$ in BM without or with LPS, GEMS-CM, $100 \mathrm{nM}$ FTY720, and $200 \mathrm{nM} \mathrm{S1P}$. The effects of the different treatments on cell proliferation (A), migration (B), and expression of CD68, IBA1, and DAPI (C) are shown. Similar results were obtained with ASP-CM, as well as with $1 \mu$ M S1P. Dotted line represents the value of untreated cells, in basal condition (CTR). Scale bar, $50 \mu \mathrm{m}$. Data are the mean $\pm \mathrm{SD}$ of at least three independent experiments. $* * P<0.01$.

collaborators demonstrated that the in vitro culture of GEMSADSCs allows the isolation of a population of stem cells with a high degree of purity. These cells fulfilled the definition of MSCs, being able to differentiate into different cells of mesoderm type, including osteogenic, chondrogenic, and adipogenic ones (such as ASP cells) [33]. Moreover, we found that the Lipogems procedure was associated to a higher expression of different antigens and cell multipotency with respect to the ASP one, in agreement with recent reports $[33,43]$. This supports that Lipogems represents a valid and efficient procedure for obtaining ADSCs with a high degree of purity and low expression of proinflammatory cytokines.

In CNS, microglia are activated by various stresses and brain injury to provide supportive signals that lead to neuronal recovery. However, the persistence of the inflammatory processes in the CNS can cause serious damages to the neural complex and compromise its functional integrity, resulting in neuronal injury and neurological diseases, such as multiple sclerosis, trauma, Parkinson's disease, and Alzheimer's disease [56,57]. There is growing evidence that the modulation of microglia activation and the brain inflammatory state in general is able to improve the symptoms of many pathological conditions and decrease the phenomenon of neurode- generation $[58,59]$. Based on these observations, microglial activation represents a potential pharmacological target to treat neurodegenerative and inflammatory diseases [60,61].

In this study, to evaluate the potential effects of ADSCs on microglia, we administered the supernatant of cultured ADSCs to resting and activated cells. Our results clearly show that ADSC-CM does not affect cell viability, but exhibits a potent anti-inflammatory effect on microglia, in a similar manner for both ASP- and GEMS-CM. Indeed, the LPSinduced inflammatory activation of microglia was counteracted by the ADSC secretome, by inhibiting multiple processes of activated microglia, including cytokine secretion, expression of molecular activation markers, cell proliferation rate, and chemotaxis. Thus, our data demonstrate that ADSC-CM exhibit potent inhibitory effect on the LPS-induced activation of microglia and prompt the maintenance of a resting phenotype.

Several studies have shown that MSCs from bone marrow are able to exert inhibitory effects toward microglia cells [41,55,62-64]. Indeed, it was shown that the CM from rat bone marrow MSC was able to significantly inhibit the LPSinduced microglia proliferation, maintain the resting phenotype, and control markedly by suppressing major microglia functions, such as the phagocytic activity and cytokine 
production [55]. In addition, it was demonstrated that bone marrow MSC-CM exerts modulation on microglia in a cell contact-independent manner, through paracrine effects [41]. Thus, despite the evidence that human MSCs from different sources diverge in their expression of cell surface proteins and display distinct differentiation patterns [65], it appears that ADSCs share with MSCs from bone marrow the capacity to produce a secretome with anti-inflammatory properties against microglia. In agreement, a recent report showed that murine AMSCs, or their CM, induced changes in microglia morphology, decrease of proinflammatory cytokines, and increase in the phagocytic activity [66]. As human adipose tissue can easily be obtained in large quantities and represents a good source of ADSCs, our results underscore the potential of ADSC secretome for the development of acellular therapeutic interventions for diseases involving excessive microglial activation.

A major finding of this study is the evidence that the antiinflammatory effects of ADSC-CM require microglial SphK/ S1P as a target. First, we found that LPS-induced proliferation of microglia was strongly inhibited by the SphK inhibitor DMS. Moreover, exogenously administered S1P was able to mimic the proliferative effect of LPS, suggesting S1P as mediator of LPS effect. It is well recognized that SphK1 plays a key role in inflammatory responses, such as production of cytokines in immune cells (see Aoki et al. [67] for a recent review). Our findings are in agreement with previous reports, showing that SphK1 microglial expression is greatly and rapidly enhanced by LPS $[11,14]$, and the evidence that blockade of SphK1 activity suppresses inflammatory responses in microglial cells $[11,14,68]$.

Further pulse studies with radiolabeled Sph demonstrated that LPS treatment of resting microglia induced not only an increase in the cellular S1P but also, most importantly, a significant elevation of S1P in the cell medium. To our knowledge, this is the first report demonstrating that microglial cells are able to extracellularly release S1P and this secretion is potentiated by LPS. This finding may be of relevance for the understanding of not only microglia inflammatory properties but also of the pathogenesis of neurodegenerative diseases.

Final experiments of this investigation show that FTY720, a functional antagonist of S1PRs [51], inhibited multiple LPSinduced proinflammatory effects in microglia and provided the novel evidence that S1P suppressed the anti-inflammatory effect of ADSC-CM, suggesting that LPS-mediated microglial activation is countered by ADSC-CM through the modulation of $\mathrm{SphK} / \mathrm{S} 1 \mathrm{P}$.

\section{Conclusions}

Overall, this study demonstrates that the proinflammatory cytokine expression level is different in adipose tissue obtained by lipoaspirate and Lipogems techniques, with Lipogems exhibiting markedly lower levels. Notwithstanding, both ADSCCM potently inhibited LPS-induced microglial activation, by reducing or halting multiple inflammation-associated microglial properties. The main novelty of this study is to show, for the first time, the SphK/S1P axis as a target of ADSC-CM in exerting its anti-inflammatory action on microglial cells. Further in vitro and in vivo studies are needed to dissect the molecular mechanisms underlying ADSC secretome modulation of S1P signalling, and to confirm this finding.

\section{Acknowledgments}

This work was supported by IRCCS Foundation Ca' Granda Ospedale Policlinico Milan and Università degli Studi di Milano, Italy. The authors thank Dr. Clara Di Vito for performing ELISAs, Dr. Letizia Venturini for assessing immunofluorescent analyses, and Prof. Giovanni Ricevuti for critical reviewing of the article.

\section{Author Disclosure Statement}

Carlo Tremolada is the inventor and pct patent holder of Lipogems. All other authors declare no competing financial interests.

\section{References}

1. Ransohoff RM and VH Perry. (2009). Microglial physiology: unique stimuli, specialized responses. Annu Rev Immunol 27:119-145.

2. Streit WJ, SD Hurley, TS McGraw and SL SempleRowland. (2000). Comparative evaluation of cytokine profiles and reactive gliosis supports a critical role for interleukin-6 in neuron-glia signaling during regeneration $\mathrm{J}$ Neurosci Res 61:10-20.

3. Sawada M, A Suzumura, H Yamamoto and T Marunouchi. (1990). Activation and proliferation of the isolated microglia by colony stimulating factor- 1 and possible involvement of protein kinase C. Brain Res 509:119-124.

4. Nimmerjahn A, F Kirchhoff and F Helmchen. (2005). Resting microglial cells are highly dynamic surveillants of brain parenchyma in vivo. Science 308:1314-1318.

5. Frank-Cannon TC, LT Alto, FE McAlpine and MG Tansey. (2009). Does neuroinflammation fan the flame in neurodegenerative diseases? Mol Neurodegener 4:47-53.

6. Hla T. (2004). Physiological and pathological actions of sphingosine 1-phosphate. Semin Cell Dev Biol 5:513-520.

7. Soliven B, V Miron and J Chun. (2011). The neurobiology of sphingosine 1-phosphate signaling and sphingosine 1phosphate receptor modulators. Neurology 76:S9-S14.

8. Kitatani K, K Iwabuchi, A Snider and L Riboni. (2016). Sphingolipids in inflammation: from bench to bedside. Mediators Inflamm 2016:7602526.

9. Schilling T, H Repp, H Richter, A Koschinski, U Heinemann, F Dreyer and C Eder. (2002). Lysophospholipids induce membrane hyperpolarization in microglia by activation of IKCa1 $\mathrm{Ca}^{2+}$-dependent $\mathrm{K}^{+}$channels. Neuroscience 109:827-835.

10. Tham CS, FF Lin, TS Rao, N Yu and M Webb. (2003). Microglial activation state and lysophospholipid acid receptor expression. Int J Dev Neurosci 21:431-443.

11. Nayak D, Y Huo, WX Kwang, PN Pushparaj, SD Kumar, EA Ling and ST Dheen. (2010). Sphingosine kinase 1 regulates the expression of proinflammatory cytokines and nitric oxide in activated microglia. Neuroscience 166:132-144.

12. Wei Y, M Yemisci, HH Kim, LM Yung, HK Shin, SK Hwang, S Guo, T Qin, N Alsharif, et al. (2011). Fingolimod provides long-term protection in rodent models of cerebral ischemia. Ann Neurol 69:119-129.

13. Giri RK, SK Selvaraj and VK Kalra. (2003). Amyloid peptide-induced cytokine and chemokine expression in THP-1 monocytes is blocked by small inhibitory RNA duplexes for early growth response-1 messenger RNA. J Immunol 170:5281-5194. 
14. Lin H, N Baby, J Lu, C Kaur, C Zhang, J Xu, EA Ling and ST Dheen. (2011). Expression of sphingosine kinase 1 in amoeboid microglial cells in the corpus callosum of postnatal rats. J Neuroinflammation 8:13-36.

15. Kimura A, T Ohmori, R Ohkawa, S Madoiwa, J Mimuro, T Murakami, E Kobayashi, Y Hoshino, Y Yatomi and Y Sakata. (2007). Essential roles of sphingosine 1-phosphate/ $\mathrm{S} 1 \mathrm{P} 1$ receptor axis in the migration of neural stem cells toward a site of spinal cord injury. Stem Cells 25:115-124.

16. Choi JW, SE Gardell, DR Herr, R Rivera, CW Lee, K Noguchi, ST Teo, YC Yung, M Lu, G Kennedy and J Chun. (2011). FTY720 (fingolimod) efficacy in an animal model of multiple sclerosis requires astrocyte sphingosine 1phosphate receptor 1 (S1P1) modulation. Proc Natl Acad Sci U S A 108:751-756.

17. Zhang Z, Z Zhang, U Fauser, M Artelt, M Burnet and HJ Schluesener. (2007). FTY720 attenuates accumulation of EMAP- $\mathrm{II}^{+}$and $\mathrm{MHC}-\mathrm{II}^{+}$monocytes in early lesions of rat traumatic brain injury. J Cell Mol Med 11:307-314.

18. Czech B, W Pfeilschifter, N Mazaheri-Omrani, MA Strobel, T Kahles, T Neumann-Haefelin, A Rami, A Huwiler and $\mathrm{J}$ Pfeilschifter. (2009). The immunomodulatory sphingosine 1phosphate analog FTY720 reduces lesion size and improves neurological outcome in a mouse model of cerebral ischemia. Biochem Biophys Res Commun 389:251-256.

19. Anthony DC, NR Sibson, D Leppert and D Piani Meier. (2010). Fingolimod (FTY720) therapy reduces demyelination and microglial activation in a focal DTH model of multiple sclerosis during the remission phase. Mult Scler 16:S283.

20. Jackson SJ, G Giovannoni and D Baker. (2011). Fingolimod modulates microglial activation to augment markers of remyelination. J Neuroinflammation 8:76.

21. Zuk PA, M Zhu, P Ashjian, DA De Ugarte, JI Huang, H Mizuno, XC Alfonso, JK Fraser, P Benhaim and MH Hedrick. (2002). Human adipose tissue is a source of multipotent stem cells. Mol Biol Cell 13:4279-4295.

22. Qin JB, KA Li, XX Li, QS Xie, JY Lin, KC Ye, ME Jiang, GX Zhang and XW Lu. (2012). Long-term MRI tracking of dual-labeled adipose-derived stem cells homing into mouse carotid artery injury. Int J Nanomedicine 7:5191-5120.

23. Marfia G, R Campanella, SE Navone, I Zucca, A Scotti, M Figini, C Di Vito, G Alessandri, L Riboni and E Parati. (2014). Potential use of human adipose mesenchymal stromal cells for intervertebral disc regeneration: a preliminary study on biglycan-deficient murine model of chronic disc degeneration. Arthritis Res Ther 16:457-462.

24. McIntosh KR, T Frazier, BG Rowan and JM Gimble. (2013). Evolution and future prospects of adipose-derived immunomodulatory cell therapeutics. Expert Rev Clin Immunol 9:175-184.

25. Franquesa M, FK Mensah, R Huizinga, T Strini, L Boon, E Lombardo, O DelaRosa, JD Laman, JM Grinyó, et al. (2015). Human adipose tissue-derived mesenchymal stem cells abrogate plasmablast formation and induce regulatory B cells independently of T helper cells. Stem Cells 33: 880-891.

26. Kapur SK and AJ Katz. (2013). Review of the adipose derived stem cell secretome. Biochimie 95:2222-2228.

27. Wei X, Z Du, L Zhao, D Feng, G Wei, Y He, J Tan, WH Lee, H Hampel, et al. (2009). IFATS collection: the conditioned media of adipose stromal cells protect against hypoxia-ischemia-induced brain damage in neonatal rats. Stem Cells 27:478-488.
28. Buehrer BM and B Cheatham. (2013). Isolation and characterization of human adipose-derived stem cells for use in tissue engineering. Methods Mol Biol 1001:1-11.

29. Montelatici E, B Baluce, E Ragni, C Lavazza, V Parazzi, R Mazzola, G Cantarella, M Brambilla, R Giordano and L Lazzari. (2015). Defining the identity of human adiposederived mesenchymal stem cells. Biochem Cell Biol 93:74-82.

30. Yoshimura K, T Shigeura, D Matsumoto, T Sato, Y Takaki, E Aiba-Kojima, K Sato, K Inoue, T Nagase, I Koshima and K Gonda. (2006). Characterization of freshly isolated and cultured cells derived from the fatty and fluid portions of liposuction aspirates. J Cell Physiol 208:64-76.

31. Dossena M, G Bedini, P Rusmini, E Giorgetti, A Canazza, V Tosetti, E Salsano, A Sagnelli, C Mariotti, et al. (2014). Human adipose-derived mesenchymal stem cells as a new model of spinal and bulbar muscular atrophy. PLoS One 9:e112746.

32. Shah FS, X Wu, M Dietrich, J Rood and JM Gimble. (2013). A non-enzymatic method for isolating human adipose tissuederived stromal stem cells. Cytotherapy 15:979-985.

33. Bianchi F, M Maioli, E Leonardi, E Olivi, G Pasquinelli, S Valente, AJ Mendez, C Ricordi, M Raffaini, C Tremolada and C Ventura. (2013). A new nonenzymatic method and device to obtain a fat tissue derivative highly enriched in pericyte-like elements by mild mechanical forces from human lipoaspirates. Cell Transplant 22:2063-2077.

34. Tremolada C, F Bianchi, C Ventura, C Di Vito, R Campanella, SE Navone, L Riboni, G Marfia and AI Caplan. (2015). Adipose mesenchymal stem cells and "regenerative adipose tissue graft" (lipogems) for musculoskeletal regeneration. Eur J Musc Dis 3:2-8.

35. Giori A, C Tremolada, R Vailati, SE Navone, G Marfia and AI Caplan. (2015). Recovery of function in anal incontinence after micro-fragmented fat graft (Lipogems $\left.{ }^{\circledR}\right)$ injection: two years follow up of the first 5 cases. CellR4 3:e1544.

36. Gutiérrez-Fernández M, L Otero-Ortega, J Ramos-Cejudo, B Rodríguez-Frutos, B Fuentes and E Díez-Tejedor. (2015). Adipose tissue-derived mesenchymal stem cells as a strategy to improve recovery after stroke. Expert Opin Biol Ther 15:873-881.

37. Chan TM, HJ Harn, HP Lin, SC Chiu, PC Lin, HI Wang, LI Ho, CP Chuu, TW Chiou, et al. (2014). The use of ADSCs as a treatment for chronic stroke. Cell Transplant 23:541-547.

38. Tajiri N, SA Acosta, M Shahaduzzaman, H Ishikawa, K Shinozuka, M Pabon, D Hernandez-Ontiveros, DW Kim, C Metcalf, et al. (2014). Intravenous transplants of human adipose-derived stem cell protect the brain from traumatic brain injury-induced neurodegeneration and motor and cognitive impairments: cell graft biodistribution and soluble factors in young and aged rats. J Neurosci 34:313-326.

39. Kolar MK, PJ Kingham, LN Novikova, M Wiberg and LN Novikov. (2014). The therapeutic effects of human adiposederived stem cells in a rat cervical spinal cord injury model. Stem Cells Dev 23:1659-1674.

40. Masgutov RF, GA Masgutova, MN Zhuravleva, II Salafutdinov, RT Mukhametshina, YO Mukhamedshina, LM Lima, HJ Reis, AP Kiyasov, A Palotás and AA Rizvanov. (2015). Human adipose-derived stem cells stimulate neuroregeneration. Clin Exp Med 6:1-11.

41. Ooi YY, ST Dheen and SS Tay. (2015). Paracrine effects of mesenchymal stem cells-conditioned medium on microglial cytokines expression and nitric oxide production. Neuroimmunomodulation 22:233-242. 
42. Yeh DC, TM Chan, HJ Harn, TW Chiou, HS Chen, ZS Lin and SZ Lin. (2015). Adipose tissue-derived stem cells in neural regenerative medicine. Cell Transplant 24:487-492.

43. Carelli S, F Messaggio, A Canazza, DM Hebda, F Caremoli, E Latorre, MG Grimoldi, M Colli, G Bulfamante, et al. (2015). Characteristics and properties of mesenchymal stem cells derived from micro-fragmented adipose tissue. Cell Transplant 24:1233-1252.

44. Navone SE, L Pascucci, M Dossena, A Ferri, G Invernici, F Acerbi, S Cristini, G Bedini, V Tosetti, et al. (2014). Decellularized silk fibroin scaffold primed with adipose mesenchymal stromal cells improves wound healing in diabetic mice. Stem Cell Res Ther 14:1-7.

45. Marfia G, SE Navone, C Di Vito, S Tabano, L Giammattei, A Di Cristofori, R Gualtierotti, C Tremolada, M Zavanone, et al. (2015). Gene expression profile analysis of human mesenchymal stem cells from herniated and degenerated intervertebral discs reveals different expression of osteopontin. Stem Cells Dev 24:320-328.

46. Riboni L, P Viani, R Bassi, P Giussani and G Tettamanti. (2001). Basic fibroblast growth factor-induced proliferation of primary astrocytes: evidence for the involvement of sphingomyelin biosynthesis. J Biol Chem 276:12797-12804.

47. Riboni L, P Viani and G Tettamanti. (2000). Estimating sphingolipid metabolism and trafficking in cultured cells using radiolabeled compounds. Methods Enzymol 311:656-682.

48. Marfia G, R Campanella, SE Navone, C Di Vito, E Riccitelli, LA Hadi, A Bornati, G de Rezende, P Giussani, et al. (2014). Autocrine/paracrine sphingosine-1-phosphate fuels proliferative and stemness qualities of glioblastoma stem cells. Glia 62:1968-1981.

49. Anelli V, R Bassi, G Tettamanti, P Viani and L Riboni. (2005). Extracellular release of newly synthesized sphingosine-1phosphate by cerebellar granule cells and astrocytes. $\mathbf{J}$ Neurochem 92:1204-1215.

50. Brinkmann V, A Billich, $\mathrm{T}$ Baumruker, $\mathrm{P}$ Heining, $\mathrm{R}$ Schmouder, G Francis, S Aradhye and P Burtin. (2010). Fingolimod (FTY720): discovery and development of an oral drug to treat multiple sclerosis. Nat Rev Drug Discov 9:883-897.

51. Mehling M, TA Johnson, J Antel, L Kappos and A BarOr. (2011). Clinical immunology of the sphingosine 1phosphate receptor modulator fingolimod (FTY720) in multiple sclerosis. Neurology 76:S20-S27.

52. Safford KM and HE Rice. (2005). Stem cell therapy for neurologic disorders: therapeutic potential of adiposederived stem cells. Curr Drug Targets 6:57-62.

53. Riazi AM, SY Kwon and WL Stanford. (2009). Stem cell sources for regenerative medicine. Methods Mol Biol 482: 55-90.

54. Fain JN. (2006). Release of interleukins and other inflammatory cytokines by human adipose tissue is enhanced in obesity and primarily due to the nonfat cells. Vitam Horm 74:443-477.

55. Yan K, R Zhang, C Sun, L Chen, P Li, Y Liu, L Peng, H Sun, K Qin, et al. (2013). Bone marrow-derived mesenchymal stem cells maintain the resting phenotype of microglia and inhibit microglial activation. PLoS One 8:e84116.

56. Konsman JP, B Drukarch and AM Van Dam. (2007). (Peri)vascular production and action of pro-inflammatory cytokines in brain pathology. Clin Sci (Lond) 112:1-25.

57. Gonzalez-Scarano F and G Baltuch. (1999). Microglia as mediators of inflammatory and degenerative diseases. Annu Rev Neurosci 22:219-240.
58. Morganti-Kossmann MC, M Rancan, PF Stahel and T Kossmann. (2002). Inflammatory response in acute traumatic brain injury: a double-edged sword. Curr Opin Crit Care 2:101-105.

59. McGeer EG and PL McGeer. (2007). The role of antiinflammatory agents in Parkinson's disease. $\underline{\text { CNS Drugs }}$ 21:789-797.

60. Hanisch UK. (2002). Microglia as a source and target of cytokines. Glia 40:140-155.

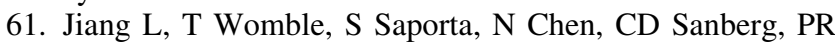
Sanberg and AE Willing. (2010). Human umbilical cord blood cells decrease microglial survival in vitro. Stem Cells Dev 19:221-228.

62. Giunti D, B Parodi, C Usai, L Vergani, S Casazza, S Bruzzone, G Mancardi and A Uccelli. (2012). Mesenchymal stem cells shape microglia effector functions through the release of CX3CL1. Stem Cells 30:2044-2053.

63. Jose S, SW Tan, YY Ooi, R Ramasamy and S Vidyadaran. (2014). Mesenchymal stem cells exert anti-proliferative effect on lipopolysaccharide-stimulated BV2 microglia by reducing tumour necrosis factor- $\alpha$ levels. J Neuroinflammation 11:149-161.

64. Liu Y, R Zhang, K Yan, F Chen, W Huang, B Lv, C Sun, L $\mathrm{Xu}, \mathrm{F}$ Li and X Jiang. (2014). Mesenchymal stem cells inhibit lipopolysaccharide-induced inflammatory responses of BV2 microglial cells through TSG-6. J Neuroinflammation 11:135-146.

65. Elahi KC, G Klein, M Avci-Adali, KD Sievert, S MacNeil and WK Aicher. (2016). Human mesenchymal stromal cells from different sources diverge in their expression of cell surface proteins and display distinct differentiation patterns. Stem Cells Int 2016:5646384.

66. Neubrand VE, M Pedreño, M Caro, I Forte-Lago, M Delgado and E Gonzalez-Rey. (2014). Mesenchymal stem cells induce the ramification of microglia via the small RhoGTPases Cdc42 and Rac1. Glia 62:1932-1942.

67. Aoki M, H Aoki, R Ramanathan, NC Hait and K Takabe. (2016). Sphingosine-1-phosphate signaling in immune cells and inflammation: roles and therapeutic potential. Mediators Inflamm 2016:8606878.

68. Zhi L, BP Leung and AJ Melendez. (2006). Sphingosine kinase 1 regulates pro-inflammatory responses triggered by $\mathrm{TNF} \alpha$ in primary human monocytes. J Cell Physiol 208:109-115.

Address correspondence to: Giovanni Marfia

Laboratory of Experimental Neurosurgery and Cell Therapy Neurosurgery Unit

Fondazione IRCCS Ca'Granda Ospedale Maggiore Policlinico University of Milan

Via Francesco Sforza 35 Milan 20122

Italy

E-mail: giovanni.marfia@unimi.it

Received for publication August 22, 2015

Accepted after revision May 23, 2016

Prepublished on Liebert Instant Online May 23, 2016 